\title{
The demographic potential of the Voronezh region as a factor of human capital development
}

\author{
Nataliya Yakovenko ${ }^{1}$, Irina Safonova ${ }^{1}$, Igor Komov ${ }^{2}$, and Olga Didenko ${ }^{2}$ \\ ${ }^{1}$ Voronezh State University of Forestry and Technologies named after G.F. Morozov, Timiryazev r., \\ 8, 394087 Voronezh, Russia \\ ${ }^{2}$ Voronezh State University, 1 Universitetskaya pl., 394018, 394087 Voronezh, Russia
}

\begin{abstract}
Population is the key object of public policy, as it forms the demographic potential, without which the development of either a country or the world economy as a whole is impossible. The study of the location of the population, the number of labour resources, sex and age structure are important government tasks, the proper implementation of which forms the potential of the population. The aim of the article is to estimate the demographic potential of Voronezh Oblast. To achieve the goal the methods of statistical analysis were used, namely: grouping, relative, average, and index methods. Results. A comprehensive assessment of the demographic potential of the region has been made. The study will make it possible to make refined forecasts of demographic development of the region.
\end{abstract}

\section{Introduction}

The protracted demographic crisis in Russia makes it important to study the demographic processes taking place in the state and its regions. A thorough analysis of the course of demographic processes at territorial levels is essential for creating favourable conditions for the formation and effective implementation of the demographic potential of the country and its regions. The study of regional specifics in Russia's demographic development, scientific analysis of changes in the demographic situation in a part of the country, region or the lowest ranking administrative-territorial unit are the basis for determining demographic policy measures at the macro- and mesoregional levels.

The population is a self-replicating system, which exists and develops thanks to natural reproduction and migratory growth. The intensity of population reproduction depends not only on the nature of its demographic behaviour, but also on the availability of those contingents and categories of population that provide or are potentially able to provide for its renewal.

It is these categories of the population that shape the demographic potential of a country by their behaviour. Many works by foreign and domestic scientists have been devoted to the study of the formation of demographic potential in different countries at different stages of human existence, as well as to the analysis of the role of demographic and structural factors [1-11].

The purpose of the article is to assess demographic potential, taking into account the age and sex structure of the population of the Voronezh region, and to identify the main opportunities for improving the process of population reproduction. 


\section{Materials and Methods}

The materials for the study were modern works of domestic and foreign scientists in the field of studying the demographic development of countries and regions and assessing demographic potential.

The main methods of research were methods of statistical analysis, namely, groupings, relative and average values, and the index method.

\section{Results and Discussion}

The vital activity of human society, from the economic, social, political and military points of view, depends above all on the quantity and quality of its main figure - the population. The population is a complex, self-replicating biosocial system, which exists and develops according to certain laws inherent in it.

The demographic development of the world's countries in different historical eras has been subject to different laws of population: natural movement, mechanical movement and social movement. Depending on the type of reproduction, the population develops according to the law of rapid or slow alternation of generations, which form the laws of demographic potential of the country. Demographic or human potential is the size of the population of a certain region (country), whose sex and age composition and demographic behaviour ensure its natural reproduction.

Analysis of the data in figure 1 shows that most of the population of Voronezh region lives in the regional centre, the urban district of Voronezh ( $44.7 \%$ of the oblast's population). The most populated districts also include the Liskinsky District (4.3\%), the Novousmansky District (3.5\%) and the Borisoglebsky Urban District (3.2\%). The town of Voronezh (1743.1 persons $/ \mathrm{km}^{2}$ ) and the City District of Borisoglebsk (682.9 persons $/ \mathrm{km}^{2}$ ) have the highest population concentration. In other municipalities of the region the population density varies from 66.6 to 10.5 persons $/ \mathrm{km}^{2}$.

The lowest population densities are found in Ternovsky, Vorobyevsky and Petropavlovsky districts. The average population density in the region is 44.6 persons $/ \mathrm{km}^{2}$.

Accordingly, it is the regions with the highest population densities that have the greatest influence on demographic trends for the region as a whole.

The most significant indicators in assessing the demographic potential of the Voronezh Region are the dynamics of life expectancy at birth, and fertility and mortality rates.

In the region as a whole, life expectancy at birth has followed a fairly positive trend, increasing by 2.33 years over the five-year observation period.

The highest value of this indicator is observed among women, from 2014 to 2017 it ranges from 76.9 to 77.7 years, in 2018 there is a slight decrease of 0.6 years in the value of the indicator. The difference in life expectancy at birth between males and females is more than 10 years, with the male population showing a more characteristic downward trend in the fiveyear observation period (fig. 3).

Life expectancy at birth is an integral indicator directly dependent on individual factors such as economic development (income, health, housing conditions, financial crises, etc.) and the social situation of the population.

The socio-economic development of the regions also has a direct impact on such important demographic indicators as fertility and mortality rates. The average value of the region's total fertility rate in 2018 was $8.33 \%$. Using the method of typology of regions by the indicator of the total fertility rate, we have identified five groups of municipalities of the Voronezh Oblast, which will help identify existing demographic problems in the region and, accordingly, timely take certain measures by local authorities to prevent them (fig. 5). 


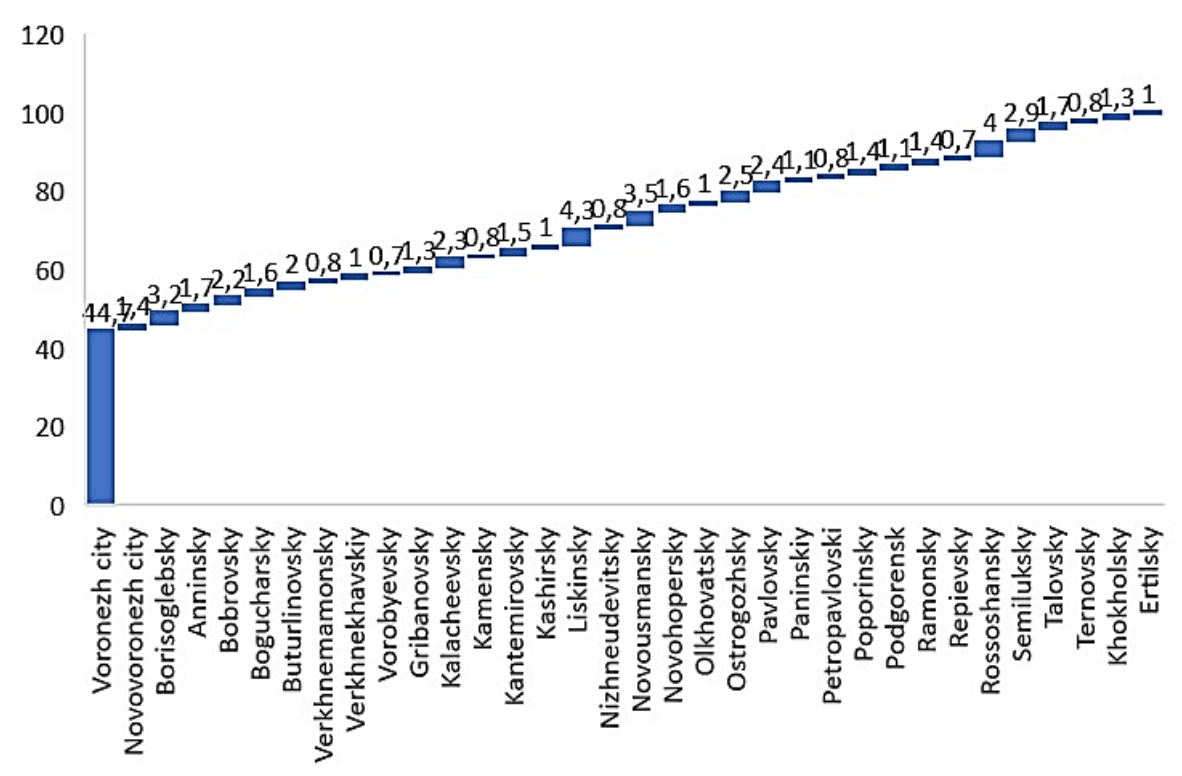

Fig. 1. Population, $\%$.

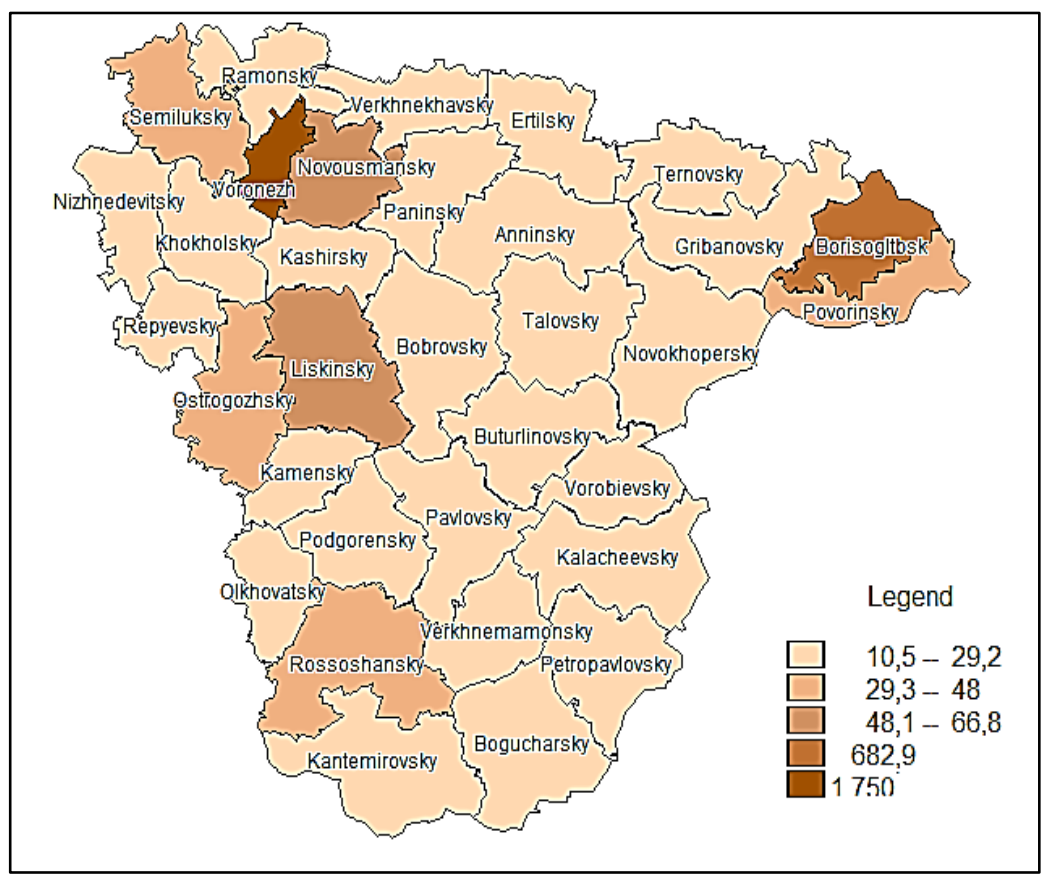

Fig. 2. Population density, persons $/ \mathrm{km}^{2}$. 


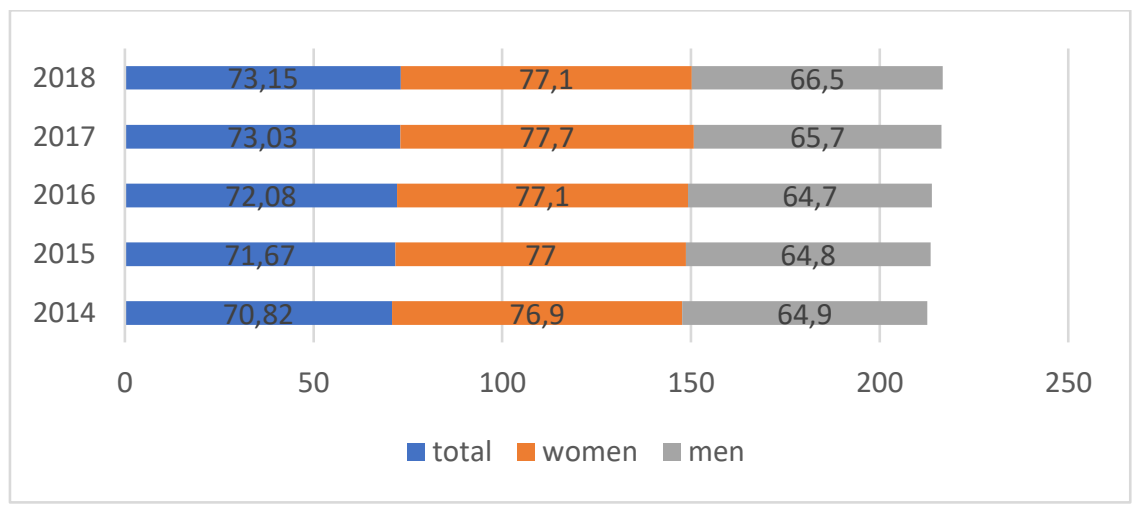

Fig. 3. Growth rate of life expectancy at birth in Voronezh region, \%.

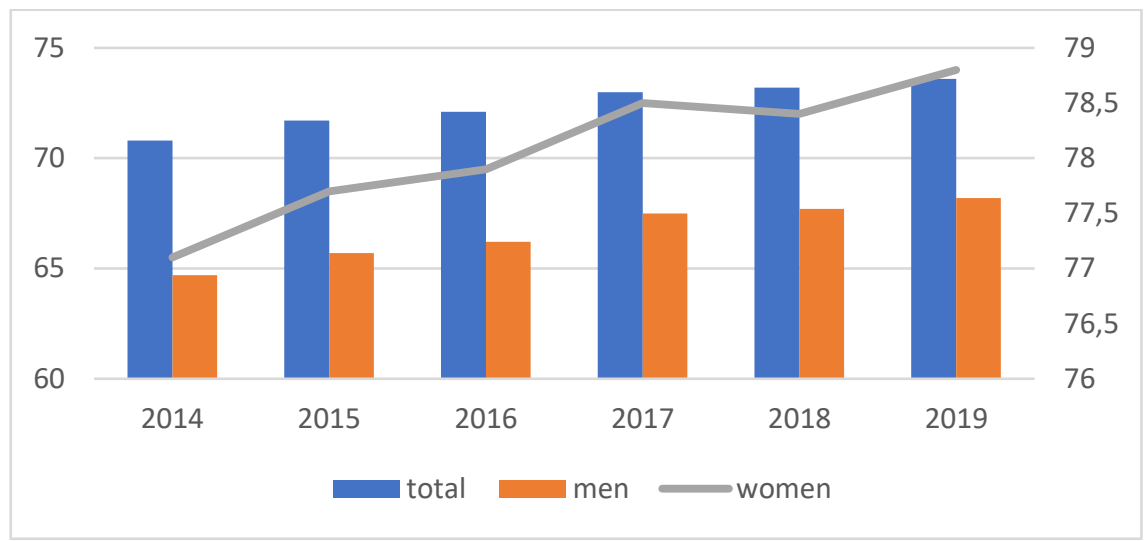

Fig. 4. Dynamics of life expectancy at birth in Voronezh region, years.

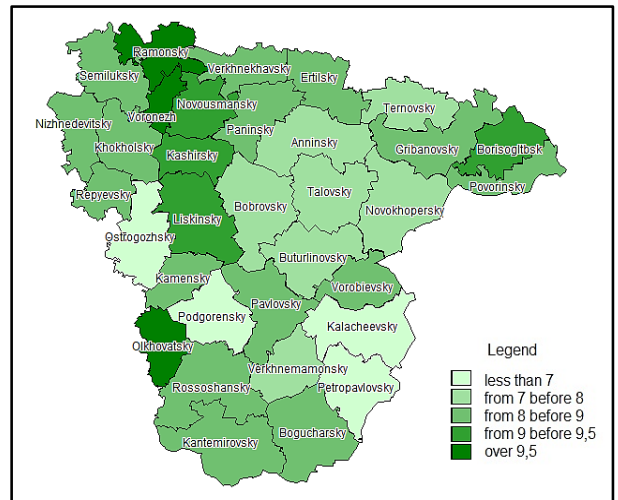

Fig. 5. Grouping of districts in Voronezh region by total fertility rate, 2018 .

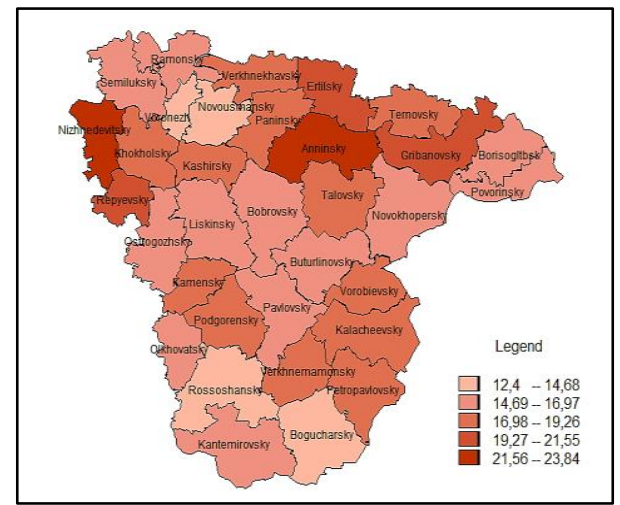

Fig. 6. Mortality rate in Voronezh region districts, 2018 (per 100,000 people).

The situation is most critical in districts with the value of the total fertility rate less than $7 \%$ [12]. This group includes 4 districts of the region - Petropavlovsky, Kalacheevsky, Ostrogozhsky and Podgorensky. Next is the group with the value of the total fertility rate slightly higher, from 7 to $8 \%$, it includes 7 municipalities of the region. The most numerous 
is the group with average values of TFR varying from 8 to $9 \%$ (15 districts). A high value of the total fertility rate, from 9 to $9.5 \%$ is observed in 5 municipal formations of the oblast, including 2 urban districts. And, finally, the maximum value of the index - over $9.5 \%$ is recorded in 3 municipalities - Olkhovatsky and Ramonsky districts, as well as urban district of Voronezh.

As for the mortality rate, the average value for the region for this indicator is $17 \%$. The maximum value is observed in Nizhnedevitsky, Anninsky and Ertilsky districts (more than $20 \% 00$ ). In exactly half of the municipal entities of the oblast the value of the total mortality rate is higher than the average, which indicates an unfavourable demographic situation. The situation is more or less favourable in the urban districts of Novovoronezh, Voronezh, as well as in Rossoshansky, Bogucharsky and Novousmansky districts (fig. 6).

The ratio of the number of deaths to births can be clearly traced through the ratio of the number of deaths to the number of births. In all municipalities of the region the number of deaths exceeds the number of births, and in three districts of the region - Anninsky, Nizhnedevitsky and Petropavlovsky - this excess is almost threefold. The most favourable situation is observed in the urban district of Voronezh (113\%), as well as in the Novousmansky and Bogucharsky districts and the urban district of Novovoronezh, which is associated with the lowest regional mortality rates in these regions and relatively high birth rates.

\section{Conclusions}

1. The Voronezh region, like many regions of the Russian Federation, is also characterized by a tense demographic situation, which is one of the most important factors for the reproduction and development of human capital. This issue creates justifiable real risks for the region and contributes to the volatility of economic and social development of its municipalities.

2. The demographic potential of the population of Voronezh Oblast is not in the best condition. The proportion and ratio of those sex groups that are capable of reproducing the population is decreasing, which means that the population has no time to renew itself, leading to the gradual extinction of the nation.

3. The age structure of the population cannot be drastically changed only by increasing the birth rate. However, there is a positive thing: the situation in the natural movement of the population, in particular the birth rate, has improved. The total number of births during the period under study has been increasing, due to positive changes in three factors, namely increasing age-specific fertility rates and improving the structure of women of childbearing age, i.e., the contribution of older age categories to the total fertility rate is increasing due to second births as well as due to the proportion of women in the total population.

4. The main objective should be to improve the qualitative structure of the population, to create opportunities to improve the quality and standard of living and to make effective use of the socio-cultural and labour potential of the elderly population.

5. A comprehensive study of the socio-economic characteristics of different age groups of people, and in particular of occupational fitness, is needed to alleviate some of the negative aspects associated with ageing.

6. In order to improve the demographic situation in the region, specific goals and policies to increase fertility and reduce mortality should be developed. The aim of regional demographic policy is to regulate the possibilities of demographic reproduction of the territory's population, to use effectively the potential of internally displaced persons, to stabilise on this basis the number and to create prerequisites for subsequent demographic growth. 


\section{Acknowledgements}

The reported study was funded by RFBR, project number 19-29-07400 мК

\section{References}

1. A. Vishnevskii, The demographic potential of Russia, Vopr Ekon (1998)

2. K.W. Wachter, Population Studies, 42(1988)

3. L. Paluch, J. Piecuch, J. Agribus. Rural Dev., 1(39) (2016)

4. L. M. Niemets, K. Yu. Segida, N.V. Husieva, Research J. "Economic Annals-XXI", 3(4) (2015)

5. L. Hersch, From current demographic to potential demographic. Gen (1944)

6. N.V. Yakovenko, Yu. V. Porosenkov, Bulletin of Voronezh State University. Series: Geography. Geoecology, 2 (2013)

7. O. Rybakovsky, O. Tayunova, Population, 2 (2019)

8. S. H. Preston, P. Donaldson, Asia-Pacific Population J., 1(2) (1986)

9. A. I. Khodykina, N. N. Reutov., Economics and Management of Innovative Technologies, 2 (65) (2017)

10. N.V. Yakovenko, O.V. Didenko, I.V. Safonova, IOP Conf. Series: Earth and Environmental Science, 272 (3) (2019)

11. N. V. Yakovenko, Ecology of urbanized territories, 1 (2007)

12. N. V. Yakovenko, I. V. Safonova, Living Standards of Population: Current Development Trends (Voronezh Oblast), 228 (2018) 